ей-

тр льные

ч стицЫ

\title{
SIMULATION OF THE EXTRACTION OF THE KINETIC PARAMETERS OF THE IONOSPHERIC PLASMA FROM THE CURRENT-VOLTAGE CHARACTERISTICS OF A CYLINDRICAL PROBE
}

\author{
Institute of Technical Mechanics \\ of the National Academy of Sciences of Ukraine and the State Space Agency of Ukraine \\ 15 Leshko-Popel St., Dnipro 49005, Ukraine; e-mail: lazuch.dn@gmail.com
}

The aim of this work is the development of a procedure for the characterization of a collisionless plasma using the current-voltage characteristic of a cylindrical probe perpendicular to the plasma flow at an arbitrary ratio of the probe and reference electrode current-collecting areas. Using familiar theoretical and experimental ion and electron current vs. probe potential relationships, a mathematical model of current collection was constructed for a probe system with cylindrical electrodes. The model includes the calculation of the reference electrode equilibrium potential as a function of the probe bias voltage. Based on this theoretical model of the current-voltage characteristic of a cylindrical probe in a supersonic flow of a low-temperature nonisothermal collisionless plasma, a procedure was developed for kinetic plasma parameter extraction using a priori information on the plasma properties and the experimental conditions. The procedure is based on the determination of the values of the charged particle temperature and density, the flow velocity, and the ion mass such that the theoretical current-voltage characteristic best fits the experimental one. The a priori information on the plasma properties and the experimental conditions is specified as restrictions on the parameters of the theoretical current-voltage characteristic.

The sensitivity of the current-voltage characteristic of cylindrical probe to small variations of the unperturbed plasma parameters was studied as function of the ratio of the probe and cylindrical reference electrode current-collecting surface areas. Quantitative characteristics of the effect of the area ratio on the currant-voltage characteristic of a cylindrical probe were obtained. Probe measurements in the ionosphere were numerically simulated. The operability of the kinetic plasma parameter extraction procedure was demonstrated. The effect of probe measurement errors on the extraction of the plasma parameters was numerically studied. Within the adopted assumptions, the reliability of unperturbed plasma parameter extraction was estimated as a function of the currentvoltage characteristic measurement accuracy. The results obtained may be used in ionospheric plasma diagnostics.

Keywords nonisothermal collisionless plasma flow, Cylindrical Langmuir probe, reference electrode, characterization, a priori information, plasma characterization reliability.

1. Boyd R. Langmuir probes onboard spacecraft. In: Plasma Diagnostics. W. lochte-Holdgreven (Ed.). Moscow: Mir, 1971. Pp. 506 - 538. (in Russian).

2. Chung P., Talbot L., Touryan K. Electric Probes in Stationary and Flowing Plasmas. Moscow: Mir, 1978. 201 pp. (in Russian).

3. Kozlov O. V. Electric Probe in Plasma. Moscow: Atomizdat, 1969. 291 pp.

4. Lazuchenkov D. M., Lazuchenkov M. M. Interpretation of probe measurements in a collisionless plasma flow. Teh. Meh. 2018. No. 1. Pp. 107-120. https://doi.org/10.15407/itm2018.01.107

5. Mott-Smith H., Langmuir I. The theory of collectors in gaseous discharges. Phys. Rev. 1926. V. 28. No 5. Pp. 727-763. https://doi.org/10.1103/PhysRev.28.727

6. Hoegy W. R., Wharton L. E, Current to a moving cylindrical electrostatic probe. Journal of Applied Physics. 1973. V. 44, No. 12. Pp. 5365-5371. https://doi.org/10.1063/1.1662157

7. Latramboise J. G. Theory of Spherical and Cylindrical Langmuir Probes in a Collisionless Maxwellian Plasma at Rest. Report, No. 100. Univ. of Toronto, Institute of Aerospace Studies. 1966. 210 pp. https://doi.org/10.21236/AD0634596

8. Godard R., Laframboise J. Total current to cylindrical collectors in collisionless plasma flow. Space Science. 1983. V. 31. No. 3. Pp. 275-283. https://doi.org/10.1016/0032-0633(83)90077-6

9. Choiniere E. Theory and experimental evaluation of a consistent steady-state kinetic model for twodimensional conductive structures in ionospheric plasmas with application to bare electrodynamic tethers in space: Ph.D. dissertation. University of Michigan, 2004. 288 pp.

10. Lazuchenkov D. N., Lazuchenkov N. M. Mathematical simulation of a supersonic collisionless plasma flow around a conducting cylinder. Teh. Meh. 2019. No. 1. Pp. 63-74. (in Russian).

https://doi.org/10.15407/itm2019.01.063

Received on November 12, 2019 in final form on November 21, 2019 